\title{
Stone size and quality of life: A critical evaluation after extracorporeal shock wave lithotripsy
}

\author{
Cahit Sahin, A. Cihangir Cetinel, Bilal Eryildirim, Murat Tuncer, Gokhan Faydaci, Kemal Sarica \\ Dr. Lutfi Kirdar Training and Research Hospital, Departments of Urology, Istanbul, Turkey.
}

\begin{abstract}
Summary Objectives: To evaluate the quality of life (QoL) of the patients after extracorporeal shockwave lithotripsy (ESWL) on a treated stone size related basis.

Methods: 90 patients undergoing ESWL for kidney stones were divided into three groups; Group 1 ( $\mathrm{n}: 30, \leq 10 \mathrm{~mm}$ ), Group 2 (n: 28, $11 \mathrm{~mm}-\leq 20 \mathrm{~mm}$ ) and Group 3 (n: 32, 20-

$25 \mathrm{~mm}$ ). During 3- months follow-up, outcome of the procedure, number of cases with emergency department visits, analgesic required, re-tretatment rates, additional procedures and the changes in the QoL were evaluated.

Results: the number of emergency department visits and mean analgesic need; re-treatment rates and additional procedures were significantly higher in Group 3. Evaluation of the QoL scores in three groups showed that cases with larger stone still had lower scores during 3-month evaluation. Conclusions: Stone size could help us to predict the possible impact of ESWL on the QoL and depending on the size of the stone treated, a well planned indication and effective management possibly by an experienced urologist could limit the changes in the QoL of the patients.
\end{abstract}

KEY WORDS: Extracorporeal shockwave lithotripsy; Quality of life; Kidney stones; Stone size.

Submitted 24 January 2015; Accepted 30 April 2015

\section{INTRODUCTION}

Urolithiasis is a worldwide health problem $(1,2)$ which typically affects the social life of the patients during their most active and productive age between 20 and 50 years $(3,4)$. In addition to the distressing pain, obstruction and recurrent infections, decreased productivity, loss of work time are the adverse outcomes of stone disease $(5,6)$.

Regarding the treatment, although ESWL has revolutionized the management of urinary calculi with its highly effective results (2), a considerable percentage of the patients may require additional procedures $(7,8)$.

Success as well as re-treatment rates after ESWL are related to some certain patient and stone related factors among which the stone sizeis the most crucial one $(8,9)$. As the stone burden increases (> $20 \mathrm{~mm}$ ), the SF-rate (SFR) decreases in a considerable extent with high reretreatment rates (6). SFR after ESWL monotherapy in patients with larger stones $(20-30 \mathrm{~mm})$ are lower than expected (33-65\%) (10). In their original study, Abe et al. reported that of the 267 patients undergoing ESWL for stones sizing between 20 and $30 \mathrm{~mm} ., 46 \%$ were SF, while residual fragment were present in 54\% (11). Thus, despite a safe and successful disintegration, depending on the stone size, SFR could vary in a considerable percent of the cases $(6,12)$. The associated symptoms and morbidity during the passage of disintegrated fragments might have significant effects on these patients' QoL $(4,13,14)$. Thus, it becomes more important that endourologists should not solely focus on the SF obtained but also on the changes in psychological, functional, social and economic life of the patients after ESWL which may possibly change well during the clinical course and the repeated sessions and/or additional procedures after ESWL $(4,5,15)$. QoL is an estimate of freedom from impairement, disability or handicap (16). The quantification of QoL has been extensively reported in patients with a wide variety of diseases and well assessed in many health problems as well as after certain medications and/or procedures (17). However, to our knowledge highly limited data regarding the QoL of the stone formers after certain endourological procedures could be derived from the literature $(13,14,18)$ and our current study is the first study focusing solely on the QoL changes in cases undergoing ESWL in a standardized and detailed manner. In this prospective study we aimed to evaluate the changes in the QoL of the patients after ESWL on a treated stone size based manner.

\section{Materials AND MEthods}

Between May 2012 and December 2012, a total of 90 patients (53 men, 37 women; M/F: 1.4) undergoing ESWL for solitary radioopaque renal pelvis stones were included into this prospective study program. Patients with established contraindications for ESWL were excluded. A detailed information about the procedure were given to all cases with an informed consent prior to ESWL. Patients were divided into three subgroups with respect to the treated stone size. Group 1 (n:30) Patients with stones sizing $\leq 10 \mathrm{~mm}$, Group 2 (n: 28) $11 \mathrm{~mm}-\leq$ $20 \mathrm{~mm}$, and Group 3 (n:32) 21-25 mm. Following routine biochemical tests; plain KUB, sonography and noncontrast computed tomography (NCCT) were per- 
formed. Stone size has been assessed by NCCT in all cases. ESWL was performed by an electromagnetic (Dornier Compact Sigma, Dornier MedTech Germany) lithotriptor with a maximum shockwave number of 3000 in a session at $120 \mathrm{kV}$ values. Outcome of ESWL was assessed after 1-week and depending on the size of fragments further sessions have been performed with a l-week interval between each ESWL session. The overall outcome of ESWL was evaluated 3 months after the last session and while the cases with no fragment(s) were accepted as SF, cases with fragments as well as with no documented disintegration after 3 successful sessions were accepted as not SF.To evaluate the cases first plain KUB and sonography were performed in all cases and NCCT was performed in a case dependant manner when needed to assess the presence and size of fragments.

Spontaneous passage rates, cases referring to ED visits, analgesic required (Diclofenac sodium $75 \mathrm{mg} I \mathrm{IM}$ at each referral); additional procedures and also the changes in the QoL were assessed during 1 and 3 months after ESWL. Changes in QoL were evaluated by giving SF$36 \circledR$ questionnaire filled at hospital conditions.

First the overall baseline QoL scores before the proce- dure were evaluated and noted then the QoL scores after SWL were obtained and compared with the baseline scores before making an inter sub-group comparison.

The Medical Outcome Study SF-36 Turkish version 1.0 was used to assess QoL (19). This questionnaire consists of 36 self-administered questions that quantify QoL using eight multi-item scales: General health (GH), Physical functioning (PF), Role physical (RP), Bodily pain (BP), Vitality (VT), Social functioning (SF), Mental health (MH) and Role emotional (RE) (20). The eight scales were scored separately from 0 to 100 , with a higher score being indicative of a better result, and these scores were used for analyses of the comparisons among the groups.

\section{Statistical Analysis}

All analyses were performed by using NCSS 2007\&PASS 2008 Statistical Software program. SF-36 domains were compared among three subgroups by One-way ANOVA. Tukey HSD test was performed to evaluate Post Hoc analysis of the parameters found to be significant. While Mann Whitney U test was used for the comparison of nonnormally distributed parameters, Kruskal Wallis test was used for the nonnormally distributed parameters.

Table 1.

Evaluation of the patient, stone characteristics, success rates, additional proceures and complications in all sub-groups.

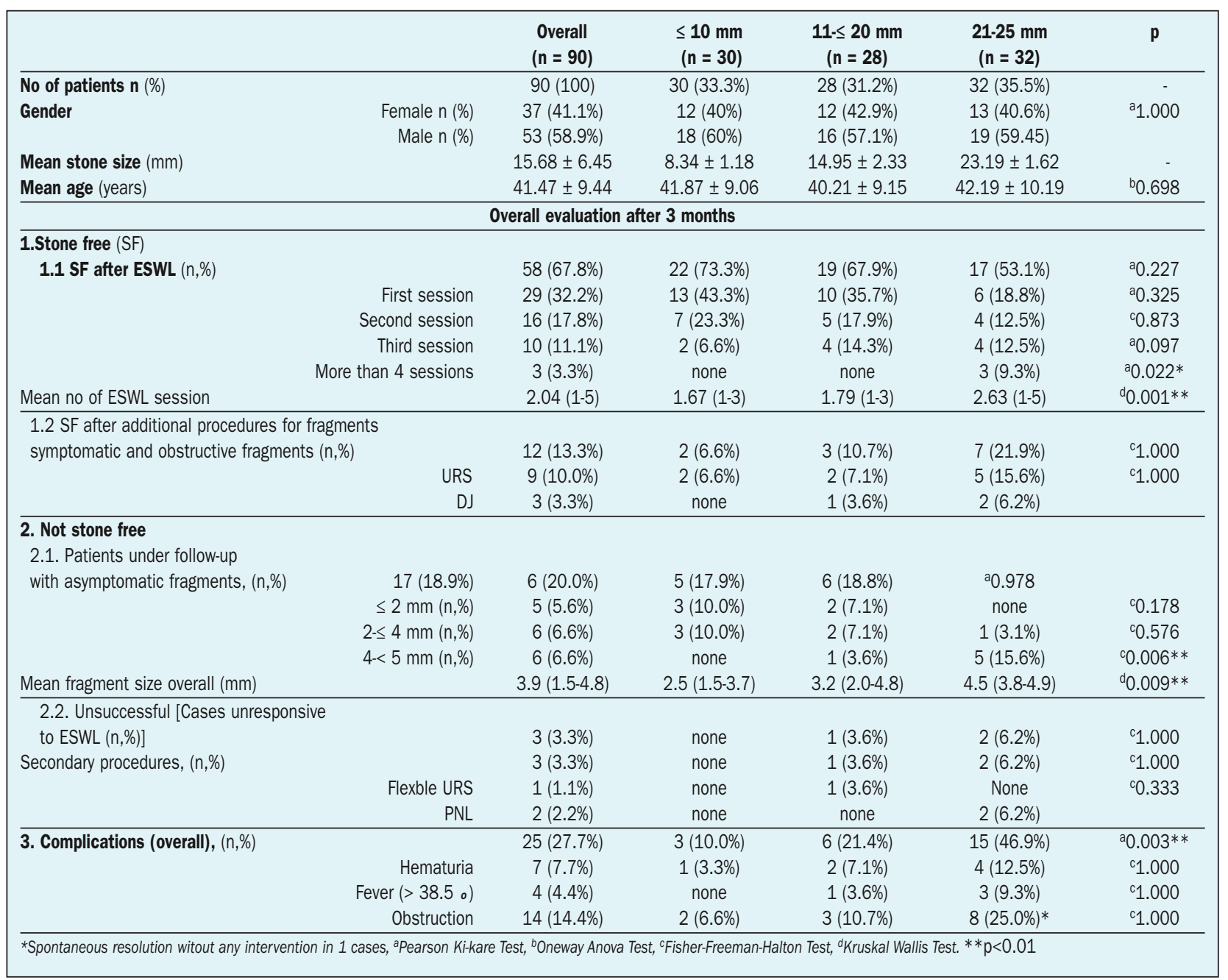


Mann Whitney U test was performed to evaluate Post Hoc analysis of the parameters found to be significant. Analysis of qualitative data was performed by Pearson Chi-square test and Fisher-Freeman-Halton Exact test. Significance was considered as $\mathrm{p}<0.05$.

\section{RESULTS}

While the mean age of the cases was 41.5 years $(24-67)$ in the study group; overall mean stone size was $15.7 \mathrm{~mm}$ $(6-25 \mathrm{~mm})$. Stone characteristics in all subgroups are given in Table 1. Stone analysis data was available in 61 patients and majority of them had calcium containing stones [Calcium oxalate monohydrate in $36(59 \%)$, calcium oxalate dihydrate in 15 (24.6\%), and mixed calcium stones in $10(16.4 \%)]$.

Evaluation of our data revealed following findings:

Patients with stones $\leq 10 \mathrm{~mm}$

Although stones were successfully disintegrated in all cases; 22 cases (73.3\%) became completely SF within 3-

\section{Table 2.}

Evaluation of the mean analgesic requirement and emergency department visit in all sub-groups.

\begin{tabular}{|c|c|c|c|c|c|}
\hline Group & & $\begin{array}{c}\leq 10 \mathrm{~mm} \\
\mathrm{n}: 30\end{array}$ & $\begin{array}{c}11-\leq 20 \mathrm{~mm} \\
\mathrm{n}: 28\end{array}$ & $\begin{array}{c}21-25 \mathrm{~mm} \\
\mathrm{n}: 32\end{array}$ & p \\
\hline \multirow[t]{2}{*}{ Mean No of ED visit } & No & $26(86.7 \%)$ & $23(82.1 \%)$ & $17(53.1 \%)$ & $\begin{array}{l}{ }^{a} p^{1-2}: 0.726 \\
{ }^{a} p^{1-3}: 0.010 * \\
{ }^{a} p^{2-3}: 0.035^{*}\end{array}$ \\
\hline & Yes & $4(13.3 \%)$ & $5(17.9 \%)$ & $15(46.9 \%)$ & \\
\hline \multicolumn{6}{|c|}{ Mean analgesic required (mg) } \\
\hline \multicolumn{2}{|c|}{ Mean \pm SD } & $22.50 \pm 52.67$ & $32.14 \pm 71.96$ & $133.59 \pm 123.07$ & $\begin{array}{c}{ }^{b} p^{1-2}: 0.785 \\
{ }^{b} p^{1-3}: 0.001^{* *} \\
{ }^{b} p^{2-3}: 0.001 * *\end{array}$ \\
\hline
\end{tabular}

Table 3.

Evaluation of the QoL scores between baseline (before ESWL) and overall values of the whole group during 1 and 3 months.

\begin{tabular}{|c|c|c|c|c|}
\hline & & $\begin{array}{l}\text { Overall group scores }(n=90) \\
\text { Mean } \pm S D\end{array}$ & $\begin{array}{l}\text { Baseline (before ESWL) scores }(n=90) \\
\text { Mean } \pm \text { SD }\end{array}$ & $\mathrm{p}$ \\
\hline \multirow[t]{2}{*}{$\overline{\mathrm{GH}}$} & 1.month & $32.67 \pm 16.27$ & $56.89 \pm 9.90$ & $0.001 * *$ \\
\hline & 3.month & $46.67 \pm 14.38$ & $56.89 \pm 9.90$ & $0.001 * *$ \\
\hline \multirow[t]{2}{*}{$\overline{P F}$} & 1.month & $58.33 \pm 18.74$ & $75.00 \pm 17.97$ & $0.001 * *$ \\
\hline & 3.month & $70.28 \pm 11.18$ & $75.00 \pm 17.97$ & $0.049 *$ \\
\hline \multirow[t]{2}{*}{$\overline{\mathrm{RP}}$} & 1.month & $53.61 \pm 19.67$ & $75.83 \pm 16.10$ & $0.001 * *$ \\
\hline & 3.month & $68.06 \pm 15.91$ & $75.83 \pm 16.10$ & $0.004 * *$ \\
\hline \multirow[t]{2}{*}{$\overline{\mathrm{BP}}$} & 1.month & $43.56 \pm 18.62$ & $67.11 \pm 13.51$ & $0.001 * *$ \\
\hline & 3.month & $67.78 \pm 16.06$ & $67.11 \pm 13.51$ & 0.060 \\
\hline \multirow[t]{2}{*}{$\overline{\mathrm{VT}}$} & 1.month & $38.61 \pm 19.53$ & $64.44 \pm 12.97$ & $0.001 * *$ \\
\hline & 3.month & $60.83 \pm 17.19$ & $64.44 \pm 12.97$ & 0.314 \\
\hline \multirow[t]{2}{*}{$\overline{S F}$} & 1.month & $53.06 \pm 20.12$ & $77.50 \pm 16.78$ & $0.001 * *$ \\
\hline & 3.month & $65.83 \pm 13.74$ & $77.50 \pm 16.78$ & $0.001 * *$ \\
\hline \multirow[t]{2}{*}{$\overline{\mathrm{MH}}$} & 1.month & $48.89 \pm 18.70$ & $68.33 \pm 17.09$ & $0.001 * *$ \\
\hline & 3.month & $69.44 \pm 10.45$ & $68.33 \pm 17.09$ & 0.315 \\
\hline \multirow[t]{2}{*}{$\overline{\mathrm{RE}}$} & 1.month & $48.33 \pm 19.40$ & $77.50 \pm 13.01$ & $0.001 * *$ \\
\hline & 3.month & $66.94 \pm 16.26$ & $77.50 \pm 13.01$ & $0.001 * *$ \\
\hline \multicolumn{5}{|c|}{$\begin{array}{l}\text { Mann Whitney } \cup \text { Test, }{ }^{*}<<0,05,{ }^{*} p<0,01 \\
G H, \text { general health. } P F \text {, physical functioning. RP, role-physical. BP, bodily pain. VT, vitality. SF, social functioning. } \\
M H \text {, mental health. RE, role-emotional. }\end{array}$} \\
\hline
\end{tabular}

months. Of the remaining 8 cases, while 6 cases (20\%) had asymptomatic fragments requiring no further management, ureteroscopic (URS) stone removal was performed in 2 cases $(6.7 \%)$ with symptomatic fragments (Table 1)

\section{Patients with stones $11 \mathrm{~mm}-\leq 20 \mathrm{~mm}$}

Stones were successfully disintegrated in 27 of 28 cases (96.4\%). While 19 cases (67.9\%) became SF within 3months, remaining 8 cases demonstrated asymptomatic fragments requiring no further management in 5 cases (17.9\%). Two cases became SF after URS stone removal (7.1\%); double-J (DJ) stent was inserted in 1 case (3.6\%) for obstructing fragments. Lastly no disintegration at all was observed in 1 case (3.6\%) and flexible URS stone disintegration was performed (Table 1).

\section{Patients with stones sizing $21 \mathrm{~mm}-25 \mathrm{~mm}$}

Stones were successfully disintegrated in 30 of 32 cases (93.7\%). However only 17 cases $(53.1 \%)$ became completely SF within 3-months. Of the remaining 13 cases, 6 (18.8\%) had asymptomatic RF requiring no further management; 7 cases were SF after URS stone removal in 5 cases $(15.6 \%)$ and DJ stent insertion in 2 case $(6.2 \%)$.

Lastly ESWLproduced no disintegration at all in 2 cases (6.2\%). Minipercutaneous nephrolithotomy (PNL) procedure was performed in these cases. The size of the fragments in all subgroups are being given in Table 1 .

\section{Analgesic use and ED visits}

While the mean amount of analgesic use was higher in Group 3, these values were relatively less in the second and the first group [p 1-2 $=0.785, \mathrm{p}$ $1-3=0.001$, p 2-3 $=0.001]$. Similarly while 15 cases (46.9\%) in Group 3 referred to ED, 5 cases (17.9\%) in Group 2 and only 4 cases (13.3\%) in Group 1 referred to ED [p 1-2 = 0.726, p $1-3=0.010$, p 2-3 $=0.035$ ] (Table 2).

\section{Data on QoL evaluated by SF-36 survey}

Data obtained at 1-month evaluation demonstrated significantly lower scores in all 8 subdomains (GH, PF, RP, BP, VT, SF, MH and RE) in three subgroups. However this evaluation at 3-month follow-up period clearly showed that this difference was significantly lower for only 5 subdomains (GH, PF, RP, SF and RE) at 3 month evaluation (Table 3).

Additionally and more importantly this evaluation was performed in all subgroups and statistically significant mean lower scores with respect 
Figure 1a.

Evaluation of QoL scores during 1-month evaluation in all sub-groups.

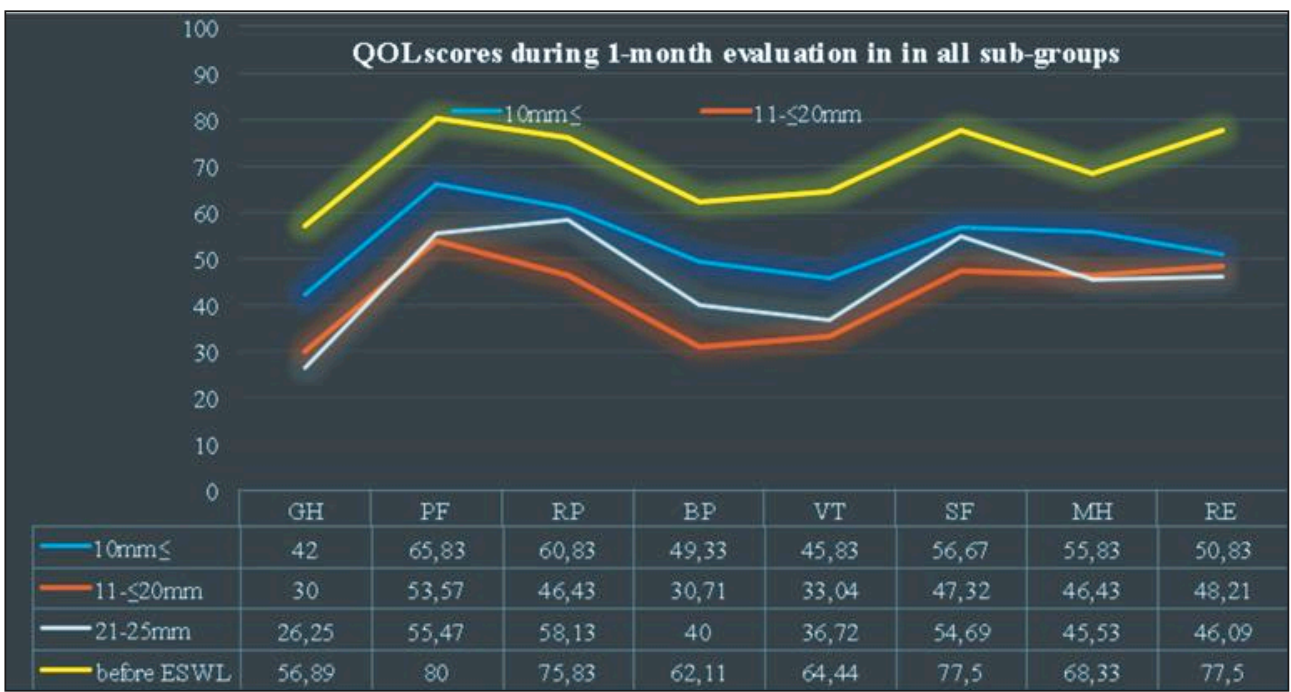

Mann Whitney $U$ Test, $p<0,05, \mathrm{GH}$, general health. PF, physical functioning. RP, role-physical. BP, bodily pain. VT, vitality. $\mathrm{SF}$, social functioning. $\mathrm{MH}$, mental health. RE, role-emotional.

Figure 1b.

Evaluation of the QoL scores during 3-month evaluation in all sub-groups

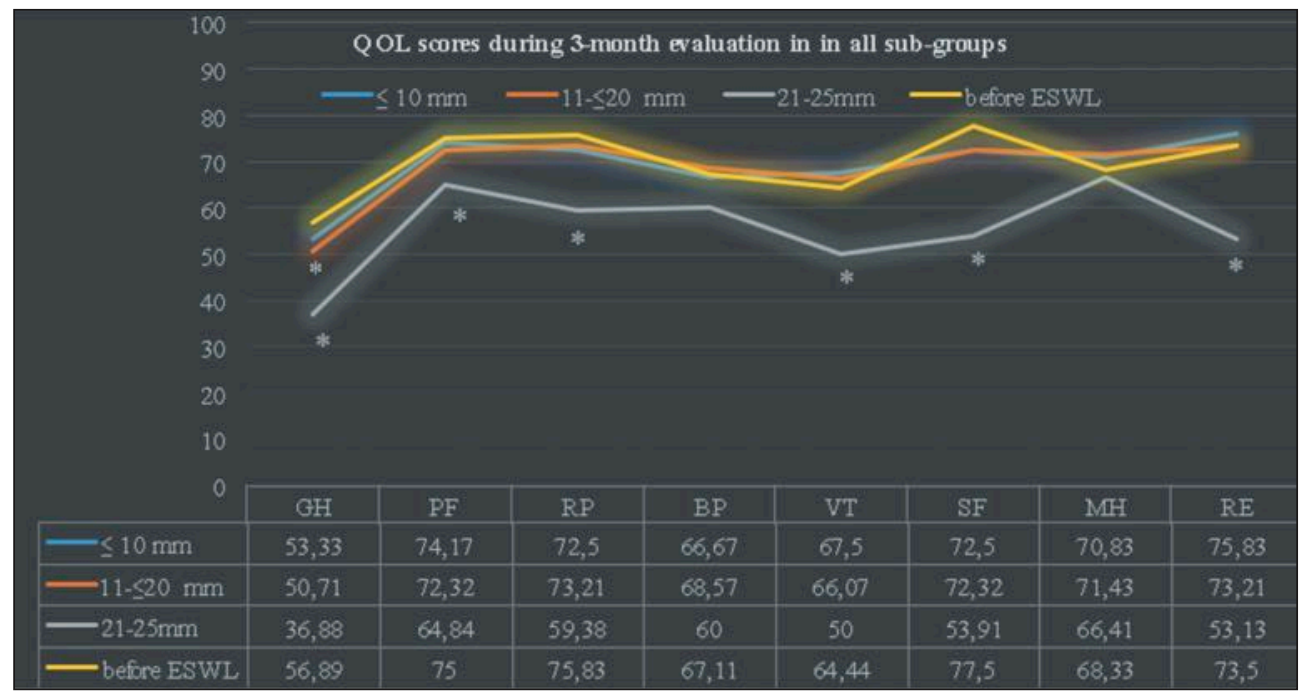

Mann Whitney U Test, $p<0,05, \mathrm{GH}$, general health. PF, physical functioning. RP, role-physical. BP, bodily pain. VT, vitality. $\mathrm{SF}$, social functioning. $\mathrm{MH}$, mental health. RE, role-emotional.

to all 8 subdomains were present in all of them during 1 month follow-up (Figure 1 a).

However, at 3-month follow-up this evaluation showed an evident improvement in the mean QoL scores of the first group $(\leq 10 \mathrm{~mm})$ where the values found to be similar to baseline (before ESWL) data. In the second group again $(11 \mathrm{~mm}-\leq 20 \mathrm{~mm})$ these scores improved in a considerable extent where there was a significant difference with respect to only one subdomain $(\mathrm{GH}, \mathrm{p}=$ 0.018).

Lastly the improvement of QoL scores in cases with larger stones (> $20 \mathrm{~mm}$ ) has been found to be highly limited with statistically significant differences in the mean values of 6 subdomains [GH $(p=0.001)$, PF $(p=0.006)$, $\mathrm{RP}(\mathrm{p}=0.001), \mathrm{VT}(\mathrm{p}=0.001), \mathrm{SF}(\mathrm{p}=0.001), \mathrm{RE}(\mathrm{p}=$ 0.001)] (Figure $1 \mathrm{~b}$ ).

\section{Discussion}

Urolithiasis is a major problem particularly in endemic countries ( 1 , 2). In addition to the disease related bothersome symptoms; fragments forming after certain stone removal procedure(s) and related interventions can also be associated with a variety of distressing symptoms which may worsen over time (15). Among these symptoms colic pain, obstruction and recurrent infections resulting in decreased productivity, loss of work time or employment are the most prominent ones $(5,6)$. Currently ESWL, URS and PNL are well-established procedures for stone removal.

Regarding the procedure related advantages and disadvantages; selection should be based on certain stone and patient related factors (2).

Although ESWL is the management of choice for most stones with its efficient and safe natüre (2); studies demonstrated that despite an effective disintegration, spontaneous passage and in some cases removal of the fragments may be needed for a completely SF status. Long-term follow-up data in large number of patients has clearly shown that $23 \%$ to $54 \%$ of the cases undergoing ESWL may have residing fragments after this procedure $(11,12)$.

Regarding the clinical course after ESWL although majority of disintegrated stone particles may pass spontaneously or stay in situ asymptomatic; they may be symptomatic and/or obstructive in a certain percent of the cases. Obstruction induced symptoms and morbidity casued by these fragments could cause significant changes in patients' QoL $(4,13,14)$. Furthermore, they may necessitate pain management, ED visits, hospitalization, or even additional procedures that may further worsen the long-term QoL.

Regarding the success rates, data in the literature show that while the SFafter ESWL monotherapy are meaningfully higher in stones sizing $<20 \mathrm{~mm}(80-85 \%)(2,6)$ 
these rates are reasonably lower (33-65\%) in larger stones $(20-30 \mathrm{~mm})(10)$. Additionally such stones may require retreatment due to incomplete disintegration resulting in a risk of partial obstruction in 19-50\% of the cases. [8] Psihramis et al. reported 52\% SF after ESWL in 674 cases with renal stones sizing $>20 \mathrm{~mm}$ with a retreatment rate of $18.6 \%$ (22).

Again, Lingeman et al. showed that the re-treatment rates increased from $10 \%$ to $33 \%$ for stones sizing of $10-20$ $\mathrm{mm}$ and 20-30 mm, respectively (23). Additionally, Abe et al. reported that of the 267 cases undergoing SWL monotherapy for larger stones (20-30 mm), while 46\% of the cases became SF, 54\% did still have RF during follow-up (11). Lastly "The American Urological Association Nephrolithiasis Clinical Guidelines Panel" data emphasized that the re-retreatment rates increases from $12 \%$ for stones $<10 \mathrm{~mm}$ up to $46 \%$ for stones $>30 \mathrm{~mm}$ (24). Finally, recommendation made by NIH Consensus Conference indicated that patients with stones $>20 \mathrm{~mm}$ were offered PNL initially due to the higher re-treatment rates and the need for auxiliary procedures (10).

Thus, the stone size is an important parameter to predict the re-treatment rates and auxiliary procedures after ESWL. However endourologists so far, followed the patients solely with respect to the success rates without giving any attention for the changes in patient's QoL. Procedure itself, stone fragments resided as well as the additional procedures required could affect the QoL and the endourologists should not solely focus on the final outcome but also on these important changes $(4,5,15)$. Such a perspective is particularly true in socially active aged cases undergoing ESWL $(13,14)$.

To our knowledge detailed data focusing on the QoL changes after ESWL therapy particularly on a treated stone size based manner is reasonably lacking. In the limited number of studies published so far the authors either evaluated QoL changes after different procedures in a comparative manner or focused on the patient preferences in the treatment of urinary stones $(14,15,26)$. In this present study, apart from the evaluation of the efficacy of ESWL, we aimed to evaluate the changes in the QoL of the patients with an emphasis on the treated stone size during 1 and 3- month follow-up period. Patients with larger stones (> $20 \mathrm{~mm}$ ) tended to have an impaired QoL as a result of the higher re-treatment rates as well as colic pain requiring ED visits forrelatively larger fragments.

Again, mean QoL scores in such patients were compared with baseline (before ESWL) scores during both 1 and 3 month follow-up and while significantly lower scores for all 8 subdomains were noted in all sub groups during 1month period; during 3-months however values in the first group were similar to baseline (before ESWL) data. Again QoL scores improved in the second group with lower values only for one subdomain $(\mathrm{GH})$. However the improvement of QoL scores in cases with larger stones (> $20 \mathrm{~mm}$ ) was highly limited with statistically significant lower mean scores in 6 subdomains. To support these findings further, mean analgesic use and the ED visits were significantly higher in patients with such stones. Thu, although ESWL is considered as the least invasive alternative for the majority of the stones, in the light of our data evaluation of the QoL of in these cases gains a meaningful importance by bringing the question in front of the endorologists as "obtaining a completely SF status after ESWL - at the expense of what?" Clinical studies published so far focused mainly on success rates in terms of SF status; possible changes in the QoL of these cases have not been subjected to any of these studies in an attempt to outline the certain factors affecting such changes. These possible changes should be kept in mind and monitored with as much attention as given for the evaluation of the final outcome of the procedure. Again, the evident QoL changes in patients with larger stones (> $20 \mathrm{~mm}$ ) may let the endourologists to consider a proper tretament plan in favour of other minimal invasive procedures in these cases.

Concerning the limitations, limited the number of cases could be the only certain drawback of our study. However, as this one is the first in the literature evaluating the QoL after ESWL in a stone size based manner; we believe that our study will certainly give an idea in defining the importance of changes in QoL a topic which was not evaluated in detail so far.

\section{Conclusions}

Although ESWL is a safe and effective procedure; despite a successful stone disintegration, higher re-treatment rates, residing fragments and additional procedures particularly in cases with relatively larger stones (> $20 \mathrm{~mm}$ ) could significantly affect the QoL of these cases. Depending on the stone size, a proper indication and effective management possibly by an experienced urologist could limit the possibility of factors responsible for the changes in the QoL.

\section{REFERENCES}

1. Bartoletti R, Cai T, Mondaini N, et al. Epidemiology and risk factors in urolithiasis. Urol Int. 2007; 79:3-7.

2. Miller NL, Lingeman JE. Management of kidney stones. BMJ. 2007; 334:468-72.

3. Tiselius HG. Epidemiology and medical management of stone disease. BJU Int. 2003; 91:758-67.

4. Gambaro G, Reis-Santos JM, Rao N. Nephrolithiasis: why doesn't our "learning" progress? Eur Urol. 2004; 45:547-56.

5. Pearle MS, Calhoun EA, Curhan GC. Urologic diseases in America project: urolithiasis. J Urol. 2005; 173:848-57.

6. Khalil MM. Which is more important in predicting the outcome of extracorporeal shockwave lithotripsy of solitary renal stones: stone location or stone burden? J Endourol. 2012; 26:535-9.

7. El-Nahas AR, El-Assmy AM, Mansour O, et al. A prospective multivariate analysis of factors predicting stone disintegration by extracorporeal shock wave lithotripsy: the value of high-resolution noncontrast computed tomography. Eur Urol. 2007; 51:1688-93.

8. Lingeman JE, Coury TA, Newman DM, et al. Comparison of results and morbidity of percutaneous nephrostolithotomy and extracorporeal shock wave lithotripsy. J Urol. 1987; 138:485-90.

9. Raynal G, Petit J, Saint F. Which efficiency index for urinary stones treatment? Urol Res. 2009; 37:237-9. 
10. Lingeman JE, Lifshitz DA, and Evan AP: Surgical management of urinary lithiasis, in Walsh PC (Ed): Campbell's Urology, 8th ed. Philadelphia, WB Saunders, 2002; vol 4, pp 3361-3451.

11. Abe T, Akakura K, Kawaguchi M, et al. Outcomes of shockwave lithotripsy for upper urinary-tract stones: a large-scale study at a single institution. J Endourol. 2005; 19:768-73.

12. El-Assmy A, El-Nahas AR, Abo-Elghar ME, et al. Predictors of success after extracorporeal shock wave lithotripsy (ESWL) for renal calculi between 20-30 mm: a multivariate analysis model. Scientific World Journal. 2006; 23:2388-95.

13. Bensalah K, Tuncel A, Gupta A, et al. Determinants of quality of life for patients with kidney stones. J Urol. 2008; 179:2238-43.

14. Arafa MA, Rabah DM. Study of quality of life and its determinants in patients after urinary stone fragmentation. Health Qual Life Outcomes. 2010; 19:119.

15. Diniz DH, Blay SL, Schor N. Anxiety and depression symptoms in recurrent painful renal lithiasis colic. Braz J Med Biol Res. 2007; 40:949-55.

16. Last JM, Spasoff RA, Harris SS. A dictionary of Epidemiology. New York, Oxford University Press. 2001, vol 4, p. 148.

17. Alonso J, Ferrer M, Gandek B, et al. Health-related quality of life associated withchronic conditions in eight countries: results from the Internation Quality of Life Assessment (IQoLA) Project. Qual Life Res. 2004; 13:283-98.

18. Penniston KL, Nakada SY. Health related quality of life differs between male and female stone formers. J Urol. 2007; 178:2435-40.

19. Kocyigit H, Aydemir O, Fisek G, et al. Validity and reliability of
Turkish version of Short form 36: A study of a patients with romatoid disorder. Journal of Drug and Therapy (in Turkish) 1999; 12:102.

20. Ware JE, Kosinski M, Gandek B. Reliability, precision, and data quality. In: SF- 36® Health Survey Manual \& Interpretation Guide. Lincoln, Rhode Island, QualityMetric Incorporated 1993, pp 7:1$7: 17$.

21. Lingeman JE, Newman D, Mertz JH, et al. Extracorporeal shock wave lithotripsy: the Methodist Hospital of Indiana experience. J Urol. 1986; 135:1134-7.

22. Psihramis KE, Jewett MA, Bombardier C, et al. Lithostar extracorporeal shock wave lithotripsy: the first 1,000 patients. Toronto Lithotripsy Associates. J Urol. 1992; 147:1006-9.

23. Lingeman, J.E. Non-staghorn renal calculi. In Urinary Calculi. Lingeman, J.E., Smith, L.H., Woods, J.R., and Newman, D.M., Eds. Lea and Febiger, Philadelphia. 1989, pp. 149-162.

24. Segura JW, Preminger GM, Assimos DG, et al. Nephrolithiasis clinical guidelines panel summary report on the management of staghorn calculi. The American Urological Association nephrolithiasisclinical guidelines panel. J Urol 1994; 151:1648-51.

25. Mays NB, Petruckevitch A, Snowdon C. Patients' quality of life following extracorporeal shock-wave lithotripsy and percutaneous nephrolithotomy for renal calculi. Int J Technol Assess Health Care. 1990; 6:633-42.

26. Kurahashi T, Miyake H, Shinozaki M, et al. Health-related quality of life in patients undergoing lithotripsy for urinary stones. Int Urol Nephrol 2008; 40:39-43.

\section{Correspondence}

Cahit Sahin, MD (Corresponding Author)

cahitsahin129@gmail.com

Gömeç sok. Sabancı -2 Sitesi Al Kat 4 Daire 24 Acıbadem/Kadıköy Istanbul, Turkey

\section{A. Cihangir Cetinel, MD}

cihangircetinel@gmail.com

Bilal Eryildirim, $M D$

bilaleryildirim@yahoo.com

Murat Tuncer, $M D$

murattuncer77@hotmail.com

Gokhan Faydaci, MD

faydacig@yahoo.com

Kemal Sarica, MD

kemalsarica@superonline.com

Dr. Lutfi Kirdar Training and Research Hospital, Departments of Urology Istanbul, Turkey 